\title{
Special Article: Physical Activity, Physical Fitness, and Cardiovascular Risk Factors in Childhood
}

Samuel S. Gidding

Thomas Jefferson University

Follow this and additional works at: https://jdc.jefferson.edu/pedsfp

Part of the Cardiology Commons, and the Pediatrics Commons Let us know how access to this document benefits you

\section{Recommended Citation}

Gidding, Samuel S., "Special Article: Physical Activity, Physical Fitness, and Cardiovascular Risk Factors in Childhood" (2007). Department of Pediatrics Faculty Papers. Paper 66.

https://jdc.jefferson.edu/pedsfp/66

This Article is brought to you for free and open access by the Jefferson Digital Commons. The Jefferson Digital Commons is a service of Thomas Jefferson University's Center for Teaching and Learning (CTL). The Commons is a showcase for Jefferson books and journals, peer-reviewed scholarly publications, unique historical collections from the University archives, and teaching tools. The Jefferson Digital Commons allows researchers and interested readers anywhere in the world to learn about and keep up to date with Jefferson scholarship. This article has been accepted for inclusion in Department of Pediatrics Faculty Papers by an authorized administrator of the Jefferson Digital Commons. For more information, please contact: JeffersonDigitalCommons@jefferson.edu. 
Physical Activity, Physical Fitness, and Cardiovascular Risk Factors in Childhood

Samuel S. Gidding, MD

Professor of Pediatrics, Jefferson Medical College

Outreach Services and Research Director, Nemours Cardiac Center, A. I. duPont Hospital for Children

Contact information:

Nemours Cardiac Center

1600 Rockland Road

Wilmington, DE 19803

$8563098508(2714$, fax $)$

sgidding@nemours.org

Running title: Physical Activity in Childhood 


\begin{abstract}
In adults, physical activity and exercise training are associated with reduced cardiovascular morbidity and mortality, a reduced likelihood of developing adverse cardiovascular risk factors, and improved insulin sensitivity. In childhood, participation in appropriate physical activity may prevent the development of cardiovascular risk factors in the future and complement treatment of existing cardiovascular risk factors including hypertension, dyslipidemia, and overweight. Exercise in children can also significantly improve insulin sensitivity independent of weight loss. These effects are mediated in overweight children by increases in lean body mass relative to fat mass and associated improvements in inflammatory mediators, endothelial function, and, the associated adverse hormonal milieu.
\end{abstract}

Key words: physical activity, exercise, children, cardiovascular risk factors, insulin resistance 
The cardiovascular benefits of physical fitness and regular physical activity are often underestimated because of the fact that benefit is best measured over decades rather than immediately after lifestyle change. In adults, studies with long term follow up demonstrate that physical fitness reduces cardiovascular risk by about $50 \%$ independent of other risk factors. ${ }^{1}$ In younger adults, physical fitness is associated with the prevention of the development of risk factors themselves, particularly Type II diabetes mellitus and the risk factors commonly called "the metabolic syndrome": hypertension, elevated triglycerides, and low HDL cholesterol. ${ }^{2}$ Regular physical activity is insulin sensitizing and is a more effective intervention in this regard than pharmacologic treatment. ${ }^{3}$ Thus, over a lifetime, the benefits of regular physical activity and fitness are additive with the prevention of risk factors in early life and the prevention of cardiovascular mortality later in life.

Nevertheless, a substantial literature on the relationship of physical activity and fitness to cardiovascular risk factors has developed. Strong et al have recently published an evidence based review of the association of physical activity and fitness on health outcomes in children. ${ }^{5}$ Cross-sectional and case control studies compare children with different levels of fitness or activity to determine the relationship of these parameters to cardiovascular risk factors. Treatment studies have children, either generally healthy or with risk factors, participate in a regular exercise program (with or without a control group) and after short term follow up, the results of the intervention on the risk factor are reported. Rarer, but most important, are longer term longitudinal studies of the impact of exercise and activity on risk factor development in the general population. Recently, intervention studies have assessed the impact of exercise on a number of mediators of 
cardiovascular risk including the hormonal milieu of obesity, endothelial function, and inflammatory markers. A parallel pediatric literature demonstrating the adverse consequences of sedentary activity, particularly prolonged time watching television, has also emerged but will not be covered in this review. ${ }^{6,7}$

The purpose of this review is to demonstrate that studies of physical fitness and activity in children generally support the finding of long term cardiovascular benefit of physical fitness and activity demonstrated in adults. This benefit, difficult to measure in children, is to be distinguished from treatment of established risk factors; here exercise is supportive but often insufficient by itself to be therapeutic. Recent comprehensive review articles will be summarized to document current knowledge with regard to the relationship of physical activity and fitness to cardiovascular risk factors in youth. Selected longitudinal studies and intervention studies that suggest particular long term benefits of physical activity or exercise, or identify physiologic mechanisms supportive of long term benefit will be highlighted. Finally, a Perspective section is included to attempt to reconcile the seemingly disappointing results of short term pediatric studies and encouraging long term studies of cardiovascular disease and diabetes mellitus prevention in adults.

\section{Limitations of Current Pediatric Research}

Studying the health benefits of regular physical activity in childhood is difficult for many reasons. Perhaps most important is the difficulty in performing long term assessments of an active lifestyle. Quantifying regular physical activity participation is not easy. Only recently have population based assessments of the physical fitness of children been attempted so little information is available to analyze secular trends. ${ }^{4}$ 
Maturation alters physical ability so the impact of regular training is often difficult to distinguish from normal growth and development. and compare fitness in a given individual at different ages throughout childhood, though normative data exist. The nature of childhood activity, with considerable energy expenditure related to free play and impulsive activity as opposed to organized training further limits accuracy of measurement and the conduct of intervention trials. Studies of children do not provide endpoints such as number of heart attacks or new cases of type 2 diabetes mellitus prevented, making assessment of true cardiovascular disease prevention benefit difficult.

\section{Measurement of Physical Activity and Fitness}

Though related, physical activity and physical fitness are not the same. Physical activity refers to a lifestyle and behaviors, that is, the regular participation in activites that expend significant energy. Physical fitness is a measurable trait that reflects ability to perform a specific task, most commonly treadmill walking/running or pedaling a bicycle against resistance. Maximal oxygen consumption (peak VO2) or other measure of endurance or performance standard is used to document individual performance.Study tools for physical activity assessment are usually questionnaires (not standardized) or provision of a supervised intervention and instruction for a specific number of days of the week. Optimally a standardized protocol that measures peak aerobic fitness is employed and a measure of fitness such as VO2 max is used in analyses. Accelerometers and other new tools for assessing daily physical activity are more commonplace. ${ }^{8}$

An important limitation of the use of both physical activity and physical fitness in risk factor algorithms is the absence of quantitiative thresholds clearly associated either with cardiovascular risk or protection from cardiac events. For other risk factors, 
quantitation has been critical to risk assessment. For example, LDL cholesterol levels below 100 to $110 \mathrm{mg} / \mathrm{dl}$ are unassociated with a significant increase in future cardiac events in adults. ${ }^{9}$ Currently there is no consensus definition for level of physical activity participation or of measurable physical fitness associated with cardiovascular health, in children.

\section{Tracking of Physical Fitness and Activity from Childhood to Adulthood}

The literature on the likelihood of children or adolescents sustaining either an active lifestyle of high levels or physical fitness into adulthood is substantially less extensive than for other cardiovascular risk factors. Studies that exist are limited in ethnic diversity and sample size. Some track children from youth to adolescence while others extend into young adulthood. In most but not all studies of physical fitness, tracking is similar to that found for other cardiovascular risk factors with tracking

coefficients ( $\mathrm{r}$ values) in the range of 0.30 to $0.60 .^{10-15}$ When components of fitness are studied, some factors such as flexibility or performance on specific tests track better than others. However self reported physical activity does not appear to track well.

\section{Blood Pressure}

The impact of exercise and fitness on blood pressure appears to be small, at least in the short term. ${ }^{16}$ In a meta analysis of short term intervention studies (the longest being 36 weeks with most substantially shorter) in healthy children, a nonsignificant reduction in resting blood pressure of about 1-3 mmHg was shown as a result of exercise. ${ }^{17}$ In studies of children with hypertension, either no change in blood pressure in the intervention/fitness group or a small change in the range of $1-5 \mathrm{mmHg}$ is usually 
shown. Importantly, no studies show a worsening of blood pressure or adverse health consequences with a fitness intervention.

Children's blood pressure is age dependent and rises throughout childhood at a rate of about $1 \mathrm{mmHg} /$ year. ${ }^{18}$ A less frequently explored question is whether or not physical activity has an impact on the age-related rise in blood pressure. There are now 4 studies of at least 18 months and up to 5 years duration separately examining children of different ages from preschool years through adolescence with monitoring of physical activity by questionnaire or by observation of participation. ${ }^{19-22}$ Collectively, these studies show a similar result as the meta analysis of intervention trials, a small effect on blood pressure of 1-2 $\mathrm{mmHg}$ in those with the highest activity. In assessing the importance of these studies one must consider the intended effect. Certainly, related to resting blood pressure the magnitude is small, but if one considers that over the course of these studies blood pressure should rise $2-3 \mathrm{mmHg}$ in each child and this rise is blunted, this suggests that the importance of fitness on blood pressure is not so much to lower blood pressure but to prevent this age-related rise. This concept is supported by data in young adults that suggests higher fitness at age 18-30 years is significantly protective against the development of future hypertension up to 15 years in the future and a recent study in high school students suggesting sports participation and physical activity prevent incident hypertension. ${ }^{2,23}$

Another potential effect of exercise on blood pressure that is less well studied is the fact that though participation in exercise raises blood pressure during the activity, ambulatory blood pressure monitored throughout the day suggests that those participating in sports have lower average daily blood pressure. ${ }^{24,25}$ This may be another subtle 
manifestation of the benefit of exercise independent of an observed direct benefit on a measured risk factor such as hypertension.

\section{Blood Lipids}

Similar to blood pressure, the short term impact of physical fitness and activity on lipids appears to be small. Though many studies have examined the effect on LDL cholesterol, there is little evidence from observational or interventional studies to suggest there is any effect of exercise in childhood on this risk factor though some pediatric and adult studies suggest a small effect. Significant but again small effects are seen in lowering triglycerides and raising HDL cholesterol in some observational and in intervention studies. ${ }^{5,26,27}$ A limitation of current pediatric data is that many of these studies are done in children with normal lipid levels, thus the prevention benefit, as opposed to the therapeutic benefit observed by change in lipid level change is never assessed. This criticism is supported by the observation that the effect on lipids appears to be dependent on the intensity of the intervention and may also be greater in those with underlying lipid disorders. In studies where insulin resistance is also measured, these beneficial effects on lipids and lipoproteins are associated with improvements in insulin sensitivity in obese children. ${ }^{28}$

There are several long term studies of the impact of physical activity/fitness on lipids and lipoproteins. One study from Finland followed individuals for 6 years and showed that long term participation in regular physical activity was associated with improved triglycerides and that the effect was attenuated by improvement in insulin sensitivity. ${ }^{29}$ In the CARDIA study, fitness level at ages18-30 years was protective against the future development of elevated triglycerides and low HDL cholesterol. ${ }^{2}$ 
A new area of interest in lipidology relates to lipoproteins with increased atherogeneicity, including small dense LDL and VLDL remnants. Increased likelihood of having more atherogenic particles is associated with high triglycerides and low HDL cholesterol as well as overweight. Currently, the author is not aware of any studies in children that have attempted to determine if exercise favorably impacts the atherogenicity of lipoproteins. The former notwithstanding, one study of young men showed a favorable impact of fitness on lipid particle distribution. ${ }^{30}$

\section{Obesity}

There is substantial evidence linking physical activity and fitness to the presence, treatment and prevention of obesity. Numerous cross sectional studies conducted in all age groups associate regular physical activity with lower BMI. Intervention studies using moderate to intense activity ranging from 3 to 7 days a week show associations with improvement in adiposity. ${ }^{5}$ Cross sectional studies of physical fitness demonstrate decreased fitness in overweight individuals, particularly those with severe obesity (body

mass index $\left.(\mathrm{BMI})>40 \mathrm{~kg} / \mathrm{m}^{2}\right) .{ }^{31}$ Interestingly, when fitness is adjusted for lean body mass, overweight children have normal fitness suggesting that considerable effort must be expended to carry the excess weight. ${ }^{32}$

Longitudinal observational studies clearly link regular participation in physical activity to long term change in weight for height and obesity prevention. For example, the National Growth and Health Study (NGHS) followed white and black girls from puberty through the end of high school. ${ }^{33}$ Investigators were clearly able to associate $\mathbf{a}$ decline in physical activity with increased overweight. The Oslo Youth Study showed participation in regular physical activity was a critical determinant of weight gain over an 
18-20 interval. ${ }^{34}$ In the Amsterdam Growth and Health Study, development of metabolic syndrome, linked with the development of obesity, was inversely related to fitness and intense physical activity. ${ }^{35}$ In a 2 year study of a combined physical activity and diet intervention, those children who lowered their standard deviation score for overweight had participated in greater physical activity and had significant improvements in cardiovascular risk profiles. ${ }^{36}$ In young adults, changes in overweight are directly related to changes in physical fitness. ${ }^{37}$

There are many interventional studies in overweight children using regular exercise from 3 to 7 days with moderately intense activity. These studies show exercise may or may not result in modest weight or body mass index reduction; however exercise does lead to reductions in total fat, visceral fat, and also increased muscle mass. ${ }^{38-40}$ In diet based weight loss programs, exercise may have additional benefits. In a randomized controlled trial by Becque et al, a comparison of diet alone versus diet and exercise interventions, the addition of regular exercise resulted in comparable weight loss in each group but better improvement in cardiovascular risk factors in the exercise group. ${ }^{41}$ In adults, a national registry of individuals reported that regular physical activity was critical to maintain weight after successful weight loss. ${ }^{42}$

\section{Insulin Sensitivity}

Insulin resistance is the cardiovascular risk factor for which exercise is a primary treatment. This relationship has been well known for decades in Type I diabetics but has assumed increasing importance as the obesity epidemic has progressed and glucose tolerance abnormalities are increasingly recognized at young ages. ${ }^{43}$ There are several recent studies showing a favorable relationship between regular exercise and insulin 
sensitivity. A cross sectional study of the interaction of fitness, insulin sensitivity, and overweight showed an important association of fitness with insulin sensitivity but this relationship was strongly mediated by fatness. ${ }^{44}$ In children of parents with Type II diabetes mellitus, fitness has been shown to have an important impact on insulin sensitivity. ${ }^{45}$ Positive effects were recognized with aerobic training, resistance training, interventions as short as 2 weeks, and school based interventions. ${ }^{46-50}$ In adults, exercise alone was effective in reducing the transition from impaired glucose tolerance to type II diabetes mellitus. ${ }^{3}$

\section{Non-traditional Risk Factors}

Investigators have looked beyond traditional risk factors to better identify how exercise mediates improvements in cardiovascular risk. ${ }^{5}$ Variables studied have included markers of inflammation (e.g. c-reactive protein), hormones associated with obesity or adipokines (adiponectin, leptin), markers of endothelial injury, and coagulation factors. Similar to studies of conventional risk factors, some studies show positive effects of exercise while others do not. For examples, two studies examined overweight children longitudinally after moderate exercise interventions; while both showed improvements in insulin sensitivity despite the absence of significant changes in weight after the exercise intervention, one was able to correlate benefits to changes in body composition, adiponectin, fibrinogen, and markers of inflammation whereas the other did not. ${ }^{47,51,52}$ Currently, studies of this type do not have sufficient sample size or consistency of findings to draw firm conclusions. More work in adult populations may provide direction for pediatric studies. In the future, this body of work may identify 
useful physiologic markers that can both demonstrate the pathways by which exercise exerts health benefit and measures of this benefit.

Studies of cardiovascular physiology may provide additional insight into the health benefits of exercise. Two studies of heart rate variability in children have shown positive effects of fitness on autonomic tone. ${ }^{53,54}$ These findings correlate with young adult studies of heart rate recovery after exercise, suggesting better parasympathetic function in those who participate in regular physical activity. ${ }^{55}$

Also intriguing are studies of endothelial function using ultrasound to assess vascular reactivity of the brachial arteries. An initial cross sectional study showed a strong relationship between vascular reactivity and endothelial function. ${ }^{56}$ There are now at least 4 reports of short to medium term exercise interventions showing consistent improvement in vascular reactivity and by implication, endothelial function in obese children. ${ }^{57-60}$

\section{Perspective}

From the author's perspective, there are 3 roles for physical activity/exercise in cardiovascular disease prevention beginning in youth. The first is the fact that higher levels of physical activity lower cardiovascular risk in adults by about $50 \%$ independent of other conventional risk factors. ${ }^{1}$ Starting early makes sense.

The second is prevention of the development of future risk. Though studies of 10 and 20 years duration extending from childhood to adulthood are rare, there is abundant evidence from medium and long term observational and the occasional intervention study to suggest higher levels of fitness and regular physical activity blunt age-related increases in blood pressure as well some adverse longitudinal changes in the lipid profile. 
Most important in this regard, high levels of physical activity are associated with prevention of obesity and obesity is the most important mediator of risk acquisition at all ages. ${ }^{61}$ Substantial education is required so the general public better understands energy balance. Many individuals equate relatively low amounts of energy expenditure with adequate exercise. Current recommendations for participation in 30 to 60 minutes of regular exercise on most days of the week are weight maintenance strategies. ${ }^{62}$ Without a decline in caloric intake, weight loss will not occur. Both the health value of weight maintenance and the importance of appropriate caloric intake are vital public health messages that must be reinforced.

Third is the role exercise or increased physical activity plays in the treatment of existing risk factors. Though increased energy expenditure alone has only a small impact on blood pressure and dyslipidemia, it is possible that increased exercise as part of a regular treatment regimen may limit the need for pharmacologic management by preventing future adverse changes in risk. Further, the fact that fitness protects independently against cardiovascular events suggests that adding regular exercise to an existing regimen will have important health benefits beyond what could be expected from pharmacologic intervention alone. Studies of this type have not been conducted in children and would be difficult because of the large sample sizes needed, but inclusion of exercise in clinical trials of pharmacologic therapy would be useful in advancing arguments for the health benefits of exercise.

There are two areas where a structured exercise program can be considered primary treatment. The first is insulin resistance. Evidence for the immediate and beneficial impact of exercise on insulin sensitivity is abundant and the effect can be 
observed within a week to a month. Given the current obesity epidemic, clinicians must overcome their reluctance to provide proper exercise counseling and monitoring of effort. The potential impact on type II diabetes mellitus prevention could be significant. Second is the observation regarding improvements in endothelial function. In childhood, atherosclerosis is present and related to risk factors but the lesions are of the early, reversible type. ${ }^{63}$ Though an abnormal level of brachial reactivity is probably undefinable, the documentation of rapid improvement of vascular reactivity with exercise intervention suggests that something positive is happening at the level of the endothelium and at a time when atherosclerosis can regress.

Tracking studies of patterns of physical activity from childhood to adulthood are discouraging with regard to society's current ability to improve participation in regular physical activity. Regular participation in physical activity declines beginning in adolescence. A physically active childhood does not guarantee an active lifestyle in the future. Unless regular physical activity is maintained, health benefits, particularly with regard to insulin sensitivity will be lost. Though fitness levels track and fitness at a young age is protective against risk development at an older age, fitness does decline over time.

For primordial prevention, defined as the prevention of the development of risk factors in the first place, physical activity is one of three important health behaviors, the other 2 being abstinence from smoking and proper nutrition. ${ }^{64,65}$ Because children spend more time in sedentary pursuits and have less school based physical activity now than in the past, it is incumbent upon those of us who understand the importance of regular physical activity to incorporate knowledge about physical activity into the training of 
physicians and treatment regimens for individual patients. Further, we must be active in public forums and with legislative bodies to make sure that the opportunity to participate in appropriate amounts of physical activity exist for all children. We must identify the best strategies to get children moving. Long term health benefits will not be sufficient motivation for children to exercise, the fun has to be there. 
Acknowledgment

I would like to thank George Kelley, DA for his critical review of the manuscript and very helpful suggestions.

\section{Bibliography}

1. Thompson PD, Buchner D, Pina IL, Balady GJ, Williams MA, Marcus BH, Berra K, Blair SN, Costa F, Franklin B, Fletcher GF, Gordon NF, Pate RR, Rodriguez BL, Yancey AK, Wenger NK. Exercise and Physical Activity in the Prevention and Treatment of Atherosclerotic Cardiovascular Disease: A Statement From the Council on Clinical Cardiology (Subcommittee on Exercise, Rehabilitation, and Prevention) and the Council on Nutrition, Physical Activity, and Metabolism (Subcommittee on Physical Activity). Circulation. 2003;107:3109-3116.

2. Carnethon MR, Gidding SS, Nehgme R, Sidney S, Jacobs DR, Jr., Liu K. Cardiorespiratory fitness in young adulthood and the development of cardiovascular disease risk factors. Jama. 2003;290:3092-100.

3. Knowler WC, Barrett-Connor E, Fowler SE, Hamman RF, Lachin JM, Walker EA, Nathan DM. Reduction in the incidence of type 2 diabetes with lifestyle intervention or metformin. N Engl J Med. 2002;346:393-403.

4. Pate RR, Wang CY, Dowda M, Farrell SW, O'Neill JR. Cardiorespiratory fitness levels among US youth 12 to 19 years of age: findings from the 1999-2002 National Health and Nutrition Examination Survey. Arch Pediatr Adolesc Med. 2006;160:1005-12.

5. Strong WB, Malina RM, Blimkie CJ, Daniels SR, Dishman RK, Gutin B, Hergenroeder AC, Must A, Nixon PA, Pivarnik JM, Rowland T, Trost S, Trudeau F. Evidence based physical activity for school-age youth. $J$ Pediatr. 2005;146:732-7.

6. Robinson TN. Reducing children's television viewing to prevent obesity: a randomized controlled trial. Jama. 1999;282:1561-7.

7. Taveras EM, Field AE, Berkey CS, Rifas-Shiman SL, Frazier AL, Colditz GA, Gillman MW. Longitudinal relationship between television viewing and leisuretime physical activity during adolescence. Pediatrics. 2007;119:e314-9.

8. Puyau MR, Adolph AL, Vohra FA, Butte NF. Validation and calibration of physical activity monitors in children. Obes Res. 2002;10:150-7.

9. Stamler J, Stamler R, Neaton JD, Wentworth D, Daviglus ML, Garside D, Dyer AR, Liu K, Greenland P. Low risk-factor profile and long-term cardiovascular and noncardiovascular mortality and life expectancy: findings for 5 large cohorts of young adult and middle-aged men and women. Jama. 1999;282:2012-8. 
10. Matton L, Thomis M, Wijndaele K, Duvigneaud N, Beunen G, Claessens AL, Vanreusel B, Philippaerts R, Lefevre J. Tracking of physical fitness and physical activity from youth to adulthood in females. Med Sci Sports Exerc. 2006;38:111420.

11. Kristensen PL, Wedderkopp N, Moller NC, Andersen LB, Bai CN, Froberg K. Tracking and prevalence of cardiovascular disease risk factors across socioeconomic classes: a longitudinal substudy of the European Youth Heart Study. BMC Public Health. 2006;6:20.

12. McMurray RG, Harrell JS, Bangdiwala SI, Hu J. Tracking of physical activity and aerobic power from childhood through adolescence. Med Sci Sports Exerc. 2003;35:1914-22.

13. Trudeau F, Shephard RJ, Arsenault F, Laurencelle L. Tracking of physical fitness from childhood to adulthood. Can J Appl Physiol. 2003;28:257-71.

14. Campbell PT, Katzmarzyk PT, Malina RM, Rao DC, Perusse L, Bouchard C. Prediction of physical activity and physical work capacity (PWC150) in young adulthood from childhood and adolescence with consideration of parental measures. Am J Hum Biol. 2001;13:190-6.

15. Kemper HC, de Vente W, van Mechelen W, Twisk JW. Adolescent motor skill and performance: is physical activity in adolescence related to adult physical fitness? Am J Hum Biol. 2001;13:180-9.

16. The fourth report on the diagnosis, evaluation, and treatment of high blood pressure in children and adolescents. Pediatrics. 2004;114:555-76.

17. Kelley GA, Kelley KS, Tran ZV. The effects of exercise on resting blood pressure in children and adolescents: a meta-analysis of randomized controlled trials. Prev Cardiol. 2003;6:8-16.

18. Wang X, Poole JC, Treiber FA, Harshfield GA, Hanevold CD, Snieder H. Ethnic and gender differences in ambulatory blood pressure trajectories: results from a 15-year longitudinal study in youth and young adults. Circulation. 2006;114:2780-7.

19. Gidding SS, Barton BA, Dorgan JA, Kimm SY, Kwiterovich PO, Lasser NL, Robson AM, Stevens VJ, Van Horn L, Simons-Morton DG. Higher self-reported physical activity is associated with lower systolic blood pressure: the Dietary Intervention Study in Childhood (DISC). Pediatrics. 2006;118:2388-93.

20. Shea S, Basch CE, Gutin B, Stein AD, Contento IR, Irigoyen M, Zybert P. The rate of increase in blood pressure in children 5 years of age is related to changes in aerobic fitness and body mass index. Pediatrics. 1994;94:465-70.

21. Boreham C, Twisk J, van Mechelen W, Savage M, Strain J, Cran G. Relationships between the development of biological risk factors for coronary heart disease and lifestyle parameters during adolescence: The Northern Ireland Young Hearts Project. Public Health. 1999;113:7-12.

22. Janz KF, Dawson JD, Mahoney LT. Increases in physical fitness during childhood improve cardiovascular health during adolescence: the Muscatine Study. Int J Sports Med. 2002;23 Suppl 1:S15-21.

23. Dasgupta K, O'Loughlin J, Chen S, Karp I, Paradis G, Tremblay J, Hamet P, Pilote L. Emergence of sex differences in prevalence of high systolic blood 
pressure: analysis of a longitudinal adolescent cohort. Circulation. 2006;114:2663-70.

24. Kaplan NM, Gidding S, Pickering TG, Wright JTJ. Task Force 5: Systemic Hypertension. In: 36th Bethesda Conference: Eligibility Recommendations for Competitive Athletes With Cardiovascular Abnormalities: JACC; 2005:1346-8.

25. Pescatello LS, Franklin BA, Fagard R, Farquhar WB, Kelley GA, Ray CA. American College of Sports Medicine position stand. Exercise and hypertension. Med Sci Sports Exerc. 2004;36:533-53.

26. Tolfrey K, Jones AM, Campbell IG. The effect of aerobic exercise training on the lipid-lipoprotein profile of children and adolescents. Sports Med. 2000;29:99-112.

27. Kelley GA, Kelley KS. Aerobic exercise and lipids and lipoproteins in children and adolescents: A meta-analysis of randomized controlled trials. Atherosclerosis. 2006.

28. Ferguson MA, Gutin B, Le NA, Karp W, Litaker M, Humphries M, Okuyama T, Riggs S, Owens S. Effects of exercise training and its cessation on components of the insulin resistance syndrome in obese children. Int J Obes Relat Metab Disord. 1999;23:889-95.

29. Raitakari OT, Porkka KV, Taimela S, Telama R, Rasanen L, Viikari JS. Effects of persistent physical activity and inactivity on coronary risk factors in children and young adults. The Cardiovascular Risk in Young Finns Study. Am J Epidemiol. 1994;140:195-205.

30. Halle M, Berg A, Baumstark MW, Keul J. Association of physical fitness with LDL and HDL subfractions in young healthy men. Int J Sports Med. 1999;20:464-9.

31. Gidding SS, Nehgme R, Heise C, Muscar C, Linton A, Hassink S. Severe obesity associated with cardiovascular deconditioning, high prevalence of cardiovascular risk factors, diabetes mellitus/hyperinsulinemia, and respiratory compromise. $J$ Pediatr. 2004;144:766-9.

32. Norman AC, Drinkard B, McDuffie JR, Ghorbani S, Yanoff LB, Yanovski JA. Influence of excess adiposity on exercise fitness and performance in overweight children and adolescents. Pediatrics. 2005;115:e690-6.

33. Kimm SY, Glynn NW, Kriska AM, Barton BA, Kronsberg SS, Daniels SR, Crawford PB, Sabry ZI, Liu K. Decline in physical activity in black girls and white girls during adolescence. N Engl J Med. 2002;347:709-15.

34. Kvaavik E, Tell GS, Klepp KI. Predictors and tracking of body mass index from adolescence into adulthood: follow-up of 18 to 20 years in the Oslo Youth Study. Arch Pediatr Adolesc Med. 2003;157:1212-8.

35. Ferreira I, Twisk JW, van Mechelen W, Kemper HC, Stehouwer CD. Development of fatness, fitness, and lifestyle from adolescence to the age of 36 years: determinants of the metabolic syndrome in young adults: the amsterdam growth and health longitudinal study. Arch Intern Med. 2005;165:42-8.

36. Reinehr T, de Sousa G, Toschke AM, Andler W. Long-term follow-up of cardiovascular disease risk factors in children after an obesity intervention. Am J Clin Nutr. 2006;84:490-6.

37. Lewis CE, Smith DE, Wallace DD, Williams OD, Bild DE, Jacobs DR, Jr. Sevenyear trends in body weight and associations with lifestyle and behavioral 
characteristics in black and white young adults: the CARDIA study. Am J Public Health. 1997;87:635-42.

38. Atlantis E, Barnes EH, Singh MA. Efficacy of exercise for treating overweight in children and adolescents: a systematic review. Int J Obes (Lond). 2006;30:102740 .

39. Reilly JJ, McDowell ZC. Physical activity interventions in the prevention and treatment of paediatric obesity: systematic review and critical appraisal. Proc Nutr Soc. 2003;62:611-9.

40. Maziekas MT, LeMura LM, Stoddard NM, Kaercher S, Martucci T. Follow up exercise studies in paediatric obesity: implications for long term effectiveness. $\mathrm{Br}$ J Sports Med. 2003;37:425-9.

41. Becque MD, Katch VL, Rocchini AP, Marks CR, Moorehead C. Coronary risk incidence of obese adolescents: reduction by exercise plus diet intervention. Pediatrics. 1988;81:605-12.

42. Wing RR, Hill JO. Successful weight loss maintenance. Annual Review of Nutrition. 2001;21:323-41.

43. Corigliano G, Iazzetta N, Corigliano M, Strollo F. Blood glucose changes in diabetic children and adolescents engaged in most common sports activities. Acta Biomed. 2006;77 Suppl 1:26-33.

44. Lee S, Bacha F, Gungor N, Arslanian SA. Cardiorespiratory fitness in youth: relationship to insulin sensitivity and beta-cell function. Obesity (Silver Spring). 2006;14:1579-85.

45. Ahn CW, Song YD, Nam JH, Kim DM, Woo SO, Park SW, Cha BS, Lim SK, Kim KR, Lee JH, Lee HC, Huh KB. Insulin sensitivity in physically fit and unfit children of parents with Type 2 diabetes. Diabet Med. 2004;21:59-63.

46. Shaibi GQ, Cruz ML, Ball GD, Weigensberg MJ, Salem GJ, Crespo NC, Goran MI. Effects of resistance training on insulin sensitivity in overweight Latino adolescent males. Med Sci Sports Exerc. 2006;38:1208-15.

47. Nassis GP, Papantakou K, Skenderi K, Triandafillopoulou M, Kavouras SA, Yannakoulia M, Chrousos GP, Sidossis LS. Aerobic exercise training improves insulin sensitivity without changes in body weight, body fat, adiponectin, and inflammatory markers in overweight and obese girls. Metabolism. 2005;54:14729.

48. Carrel AL, Clark RR, Peterson SE, Nemeth BA, Sullivan J, Allen DB. Improvement of fitness, body composition, and insulin sensitivity in overweight children in a school-based exercise program: a randomized, controlled study. Arch Pediatr Adolesc Med. 2005;159:963-8.

49. Chen AK, Roberts CK, Barnard RJ. Effect of a short-term diet and exercise intervention on metabolic syndrome in overweight children. Metabolism. 2006;55:871-8.

50. Monzavi R, Dreimane D, Geffner ME, Braun S, Conrad B, Klier M, Kaufman FR. Improvement in risk factors for metabolic syndrome and insulin resistance in overweight youth who are treated with lifestyle intervention. Pediatrics. 2006;117:e1111-8. 
51. Balagopal P, George D, Patton N, Yarandi H, Roberts WL, Bayne E, Gidding S. Lifestyle-only intervention attenuates the inflammatory state associated with obesity: a randomized controlled study in adolescents. J Pediatr. 2005;146:342-8.

52. Balagopal P, George D, Yarandi H, Funanage V, Bayne E. Reversal of obesityrelated hypoadiponectinemia by lifestyle intervention: a controlled, randomized study in obese adolescents. J Clin Endocrinol Metab. 2005;90:6192-7.

53. Gutin B, Owens S, Treiber F, Islam S, Karp W, Slavens G. Weight-independent cardiovascular fitness and coronary risk factors. Arch Pediatr Adolesc Med. 1997;151:462-5.

54. Gutin B, Barbeau P, Litaker MS, Ferguson M, Owens S. Heart rate variability in obese children: relations to total body and visceral adiposity, and changes with physical training and detraining. Obes Res. 2000;8:12-9.

55. Carnethon MR, Jacobs DR, Jr., Sidney S, Sternfeld B, Gidding SS, Shoushtari C, Liu K. A longitudinal study of physical activity and heart rate recovery: CARDIA, 1987-1993. Med Sci Sports Exerc. 2005;37:606-12.

56. Abbott RA, Harkness MA, Davies PS. Correlation of habitual physical activity levels with flow-mediated dilation of the brachial artery in 5-10 year old children. Atherosclerosis. 2002;160:233-9.

57. Watts K, Beye P, Siafarikas A, O'Driscoll G, Jones TW, Davis EA, Green DJ. Effects of exercise training on vascular function in obese children. $J$ Pediatr. 2004;144:620-5.

58. Meyer AA, Kundt G, Lenschow U, Schuff-Werner P, Kienast W. Improvement of early vascular changes and cardiovascular risk factors in obese children after a six-month exercise program. J Am Coll Cardiol. 2006;48:1865-70.

59. Kelly AS, Wetzsteon RJ, Kaiser DR, Steinberger J, Bank AJ, Dengel DR. Inflammation, insulin, and endothelial function in overweight children and adolescents: the role of exercise. J Pediatr. 2004;145:731-6.

60. Woo KS, Chook P, Yu CW, Sung RY, Qiao M, Leung SS, Lam CW, Metreweli $\mathrm{C}$, Celermajer DS. Effects of diet and exercise on obesity-related vascular dysfunction in children. Circulation. 2004;109:1981-6.

61. Mahoney LT, Lauer RM, Lee J, Clarke WR. Factors affecting tracking of coronary heart disease risk factors in children. The Muscatine Study. Ann N Y Acad Sci. 1991;623:120-32.

62. Daniels SR, Arnett DK, Eckel RH, Gidding SS, Hayman LL, Kumanyika S, Robinson TN, Scott BJ, St Jeor S, Williams CL. Overweight in children and adolescents: pathophysiology, consequences, prevention, and treatment. Circulation. 2005;111:1999-2012.

63. McMahan CA, Gidding S, Malcom GT, Tracy RE, Strong JP, McGill HC, Jr. PDAY risk scores are associated with early as well as advanced atherosclerosis. Pediatrics. 2006. In press.

64. Williams CL, Hayman LL, Daniels SR, Robinson TN, Steinberger J, Paridon S, Bazzarre T. Cardiovascular Health in Childhood: A Statement for Health Professionals From the Committee on Atherosclerosis, Hypertension, and Obesity in the Young (AHOY) of the Council on Cardiovascular Disease in the Young, American Heart Association. Circulation. 2002;106:143-160.

65. Gidding SS. One small step for man...? J Pediatr. 2004;145:719-20. 
